\title{
Teacher Stress and Teacher Self-Efficacy as Predictors of Engagement, Emotional Exhaustion, and Motivation to Leave the Teaching Profession
}

\author{
Einar M. Skaalvik, Sidsel Skaalvik \\ Norwegian University of Science and Technology, Trondheim, Norway \\ Email: einar.skaalvik@svt.ntnu.no
}

Received 25 May 2016; accepted 15 August 2016; published 18 August 2016

Copyright (C) 2016 by authors and Scientific Research Publishing Inc.

This work is licensed under the Creative Commons Attribution International License (CC BY). http://creativecommons.org/licenses/by/4.0/

(c) (i) Open Access

\section{Abstract}

The purpose of this study was to explore how seven potentially stressful school context variables (potential stressors) predicted senior high school teachers' experiences of teacher self-efficacy, emotional stress, emotional exhaustion, engagement in teaching, and motivation to leave the teaching profession. A total of 523 Norwegian teachers in senior high school participated in the study. Four of the potential stressors were significantly but differently related to self-efficacy and emotional stress and indirectly to emotional exhaustion, engagement, and motivation to leave the profession. The study shows that different potential stressors predict emotional exhaustion, engagement, and motivation through different psychological processes. SEM-analysis indicated two main routes to teachers' motivation to leave the profession: 1) one route from time pressure via emotional stress and exhaustion to motivation to quit and 2) another route from lack of supervisory support and trust, low student motivation and value conflicts via lower self-efficacy and lower engagement to motivation to quit.

\section{Keywords}

Teacher Stress, Teacher Self-Efficacy, Emotional Exhaustion, Teacher Engagement

\section{Introduction}

Although the quality of education is emphasized globally many countries experience a shortage of qualified teachers (e.g., Ingersoll, 2001; Hong, 2012). This problem is increasing because of teacher attrition—the depar- 
ture of teachers from their teaching jobs. Many teachers leave school for non-retirement reasons. One reason for leaving the teaching profession is stressful working conditions (Weiss, 1999). Indeed, recent research in different countries indicates that teaching is a particularly stressful occupation and that teacher stress is an international phenomenon (Chan, 2002; Johnson, Cooper, Cartwright et al., 2005; Liu \& Onwuegbuzie, 2012; Montgomery \& Rupp, 2005; Stoeber \& Rennert, 2008). Teacher stress may have devastating consequences both for the teachers and the quality of education. Possible consequences of teacher stress are reduced teacher selfefficacy (Klassen, Wilson, Siu et al., 2013), lower job satisfaction (Collie, Shapka, \& Perry, 2012), lower levels of commitment (Klassen et al., 2013), higher levels of burnout (Betoret, 2009), and increased teacher attrition (Skaalvik \& Skaalvik, 2011a).

One purpose of this study was to explore how different potential stressors at school predicted senior high school teachers' experiences of emotional stress and teaching self-efficacy. Another purpose was to examine how teacher stress and teacher self-efficacy were related to emotional exhaustion, engagement in teaching, and motivation to leave the teaching profession.

\section{Theoretical Framework}

\subsection{Teacher Stress}

Teacher stress is often defined as the experience by a teacher of unpleasant emotions resulting from aspects of the work as a teacher (Collie, Shapka, \& Perry, 2012; Kyriacou, 1987, 2001; Liu \& Onwuegbuzie, 2012). This conceptualization of teacher stress has led researchers to explore aspects of the work situation that may be experienced as stressful. Such aspects are often termed stressors (Betoret, 2006) or job demands (Hakanen, Bakker, \& Schaufeli, 2006). A number of potential stressors have been identified in empirical studies including student misbehavior or discipline problems, time pressure and workload, poor student motivation, large student diversity, conflicts with colleagues, lack of administrative support, and value conflicts (e.g., Betoret, 2009; Fernet, Guay, Senécal et al., 2012; Friedman, 1995; Hakanen et al., 2006; Klassen \& Chiu, 2011; Kokkinos, 2007; Skaalvik \& Skaalvik, 2009, 2011a, 2011b). Several of these stressors were also found in two recent semi-structured interview studies. Shernoff, Mehta, Atkins et al. (2011) interviewed 14 urban US teachers and found nine main sources of stress, for instance: disruptive student behavior, excessive workload, student diversity, limited resources and support, school-level disorganization, and accountability policies. In an open ended interview of 34 Norwegian teachers and former teachers Skaalvik and Skaalvik (2015) found seven categories of stressors that was identified by more than half of the teachers: disruptive student behavior, workload and time pressure, student diversity and working to adapt teaching to students' needs, lack of autonomy, lack of shared goals and values, problems and conflicts related to teamwork, and lack of status. Skaalvik and Skaalvik (2015) reported that teachers at different ages experienced the same stressors at school, but that senior teachers needed increasingly more time to recover from stress.

Teacher stress has in quantitative research been defined and indicated differently by different researchers. Some researchers define stress in terms of perceived stressors in the school environment, for instance disruptive student behavior, and measure stress by asking teachers about the sources of stress in the school environment (Collie, Shapka, \& Perry, 2012; Gilbert et al., 2014; Klassen \& Chiu, 2010, 2011; Klassen et al., 2013; Yoon, 2014). For instance, one item used by Collie et al. (2012) was "How great a source of stress is maintaining class discipline?” Other researchers identify potential stressors in school and ask to what degree teachers perceive the potential stressors to be present in the school environment. (Fernet, Guay, Senécal, \& Austin, 2012; Helms-Lorenz, Slof, Vermue, \& Canrinus, 2011; Skaalvik, 2007; Skaalvik \& Skaalvik, 2010, 2011a). For instance, one item used by Skaalvik and Skaalvik (2011a) was "My teaching is often disturbed by students who lack discipline”. Instead of asking directly about stress or how great a source of stress each potential stressor is these researchers estimate statistically to which degree the potential stressors are associated with outcomes like stress, job satisfaction, engagement, burnout, and motivation to leave the teaching profession. For instance, in a SEM analysis of data from 806 Canadian teachers, Fernet et al. (2012) found that teacher self-efficacy was negatively predicted by teachers' perception of student misbehaviour $(\beta=-.46)$. Using a third approach some researchers ask more generally to what degree teachers feel stress at work, feel overburdened etc. (e.g., Schwarzer \& Hallum, 2008). We conceptualize such measures as general indications of emotional stress which may result from perceived stressors in the school environment.

In this study we defined teacher stress as the experience of unpleasant emotions (which we term emotional 
stress) resulting from aspects of the work as a teacher (which we term potential stressors). Our approach was to measure both the perception of potential stressors at work (e.g., the perception of having discipline problems) and the experience of emotional stress. This approach allows us to estimate how different potential stressors contribute to emotional stress.

\subsection{Teacher Self-Efficacy}

Teacher self-efficacy is in contemporary educational research founded on social cognitive theory (Bandura, 1977, 1997, 2006). According to Zimmerman and Cleary (2006) self-efficacy is a belief about what a person can do and how well he or she can do it (see also Bong \& Skaalvik, 2003; Skaalvik, 1997). Within this perspective self-efficacy is seen as a multidimensional construct and as the most central mechanism of human agency-the ability to influence intentionally one's functioning and life circumstances (Bandura, 2006). It determines how environmental opportunities and impediments are perceived and therefore influences peoples' goals, values, and behavior (Bandura, 2006; Schunk \& Meece, 2006). Bandura emphasizes that people with low self-efficacy tend to magnify possible problems and threats and dwell with their shortcomings. Thus, we may expect teacher selfefficacy to be negatively associated with teacher stress.

Based on social cognitive theory Tschannen-Moran \& Woolfolk Hoy (2001: p. 783) defined teacher selfefficacy as a teacher's "judgment of his or her capabilities to bring about desired outcomes of student engagement and learning, even among those students who may be difficult or unmotivated.” Skaalvik (2007, p. 612) offered a similar definition as "individual teachers' beliefs in their own ability to plan, organize, and carry out activities that are required to attain given educational goals.”

The most influential source of teacher self-efficacy is previous mastery experiences-previous experiences with succeeding or failing on activities which are similar to the present activity. Other sources are vicarious experiences (e.g., observing other teachers mastering similar challenges), verbal persuasion (e.g., social support from colleagues and the school administration), and physiological arousal (e.g., a teacher noticing heartbeat when facing a challenge). Moreover, self-efficacy is a situation specific construct and fluctuates depending on for instance the perceived difficulty of the task, which resources are available, the perception of obstacles, and the time allocated for the task. Therefore, a teachers' self-efficacy may be influenced by his or her perception of stressors (obstacles) in the environment which may make the task more difficult to conduct. For instance, a math teacher who based on previous experiences expect the students to be active and motivated for working with mathematics problems will likely have higher self-efficacy for teaching mathematics than a teacher who expect the students to be unmotivated and to pay little attention to the instruction. Supporting this expectation recent research indicates that teacher self-efficacy is negatively related to teachers' perception of stressors in the school environment, for instance discipline problems (Collie et al., 2012; Fernet, Guay, Senécal, \& Austin, 2012; Gilbert et al., 2014; Klassen \& Chiu, 2010, 2011; Klassen et al., 2013; Skaalvik \& Skaalvik, 2010; Yoon, 2014).

A number of international studies show that teacher self-efficacy predicts higher teacher engagement and job satisfaction, lower levels of burnout, and less intention of leaving the teaching profession (e.g., Avanzi, Miglioretti, Velasco et al., 2012; Brouwers \& Tomic, 2000; Collie, Shapka, \& Perry, 2012; Gilbert, Adesope, \& Schroeder, 2014; Klassen \& Chiu, 2010; Klassen et al., 2013; Saricam \& Sakiz, 2014; Skaalvik, 2007; Skaalvik \& Skaalvik, 2010, 2014). These results are in accordance with the notion that self-efficacy determines how environmental opportunities and impediments are perceived and that it influences peoples' goals, values, and behavior (Bandura, 2006).

\subsection{Emotional Exhaustion}

Emotional exhaustion is characterized by low energy and chronic fatigue and is regarded the que dimension of burnout (Maslach, Jackson \& Leiter, 1996; Pines \& Aronson, 1988). Burnout is conceptualized as resulting from long term occupational stress (Jennett, Harris, \& Mesibov, 2003) and is often described as a syndrome of emotional exhaustion, depersonalization, and reduced personal accomplishment (Brouwers \& Tomic, 2000; Maslach and Jackson, 1981; Maslach, Jackson, \& Leiter, 1996). Several studies show that measures of burnout among teachers predict both subjective and objective health as well as teachers' motivation and job satisfaction. For instance, Hakanen, Bakker, \& Schaufeli (2006) showed that both exhaustion and cynicism (depersonalization) correlated negatively with self-rated health as well as work ability among Finish teachers. Available research also shows a negative relation between burnout and motivation for teaching (e.g., Hakanen et al., 2006). More- 
over, Leung and Lee (2006) found, in a study of teachers in Hong Kong, that the exhaustion dimension of burnout predicted teachers' intentions of leaving the profession. We expected that emotional exhaustion would be positively predicted by emotional stress. We also expected that emotional exhaustion would predict engagement negatively and motivation to leave the teaching profession positively.

\subsection{Work Engagement}

Work engagement refers to a positive, fulfilling, work-related state of mind that is characterized by vigor, dedication, and absorption (Bakker, Albrecht, \& Leiter, 2011; Schaufeli \& Bakker, 2010). Bakker et al. (2011) particularly emphasize the experience of energy (vigor) and the perception of the work as a significant and meaningful pursuit. Previous research shows that teacher engagement is positively predicted by teacher self-efficacy and negatively predicted by emotional exhaustion (Skaalvik \& Skaalvik, 2014). Research evidence also shows that work engagement is associated with positive outcomes, for instance lower intentions of leaving the teaching profession (Skaalvik \& Skaalvik, 2009; Bakker \& Bal, 2010; Demerouti \& Cropanzano, 2010). We expected that the potential stressors would be indirectly related to engagement, mediated through teacher self-efficacy. In turn, we expected engagement to predict motivation to leave the teaching profession negatively. We also expected that emotional stress would predict engagement indirectly, through emotional exhaustion.

\subsection{Motivation to Leave the Teaching Profession}

As noted in the introduction, many teachers leave school for non-retirement reasons. Because the high attrition rate may have serious consequences for the quality of education it is important to understand the reasons that teachers leave the teaching profession. In an analysis of leavers (teachers who left the profession during the first five years) and stayers (teachers who were still teaching after five years), Hong (2012) found that the leavers had weaker self-efficacy beliefs compared to stayers and that they reported receiving less administrative or supervisory support. Teachers' intention or motivation to leave the profession is also strongly predicted by job dissatisfaction and by stressful working conditions (Skaalvik \& Skaalvik, 2011a; Weiss, 1999). Skaalvik and Skaalvik (2001a) also found that time pressure and discipline problems were indirectly related to teachers' motivation to leave the profession and that the indirect relations were mediated through emotional exhaustion and lower job satisfaction. They also found that supervisory support and positive relations with colleagues predicted lower motivation to leave the profession, mediated through stronger feeling of belonging and higher job satisfaction. Liu and Onwuegbuzie (2012) also reported stress as a primary reason for wishing to leave the teaching profession.

\subsection{The Present Study}

In the present study we explored relations between senior high school teachers' perception of seven potential stressors in school and their teaching self-efficacy as well as their experiences of emotional stress, exhaustion, engagement, and motivation to leave the teacher profession. A problem with previous studies of stressors in the teaching profession is that most studies include only a few stressors making it difficult to estimate the relative impact of different stressors. Moreover, previous research on teacher stress has focused on elementary and middle school teachers whereas research on teachers at the senior high school level is lacking.

The potential stressors included in this study were: discipline problems, time pressure, low student motivation, conflict with colleagues, lack of supervisory support and trust, student diversity, and value conflict (a teachers' feeling that the prevailing goals and values at the school are incompatible with her or his personal goals and values). We expected that the perception of stressors would be negatively related to teacher self-efficacy and positively related to emotional stress. Based on our analysis (see above) we also expected the perceived stressors to be indirectly related to exhaustion, engagement, and motivation to leave the teaching profession-mediated through self-efficacy and emotional stress. The unpleasant emotions which characterize emotional stress may include anxiety and are energy-consuming. We therefore expected emotional stress to predict emotional exhaustion positively and engagement negatively. In contrast, we expected teachers with high self-efficacy to be more engaged in teaching than teachers with low self-efficacy whereas we expected emotional exhaustion to predict engagement negatively. We also expected that teachers' motivation to leave the teaching profession would be positively predicted by emotional exhaustion and negatively by engagement. These predictions are illustrated in a theoretical model in Figure 1. 


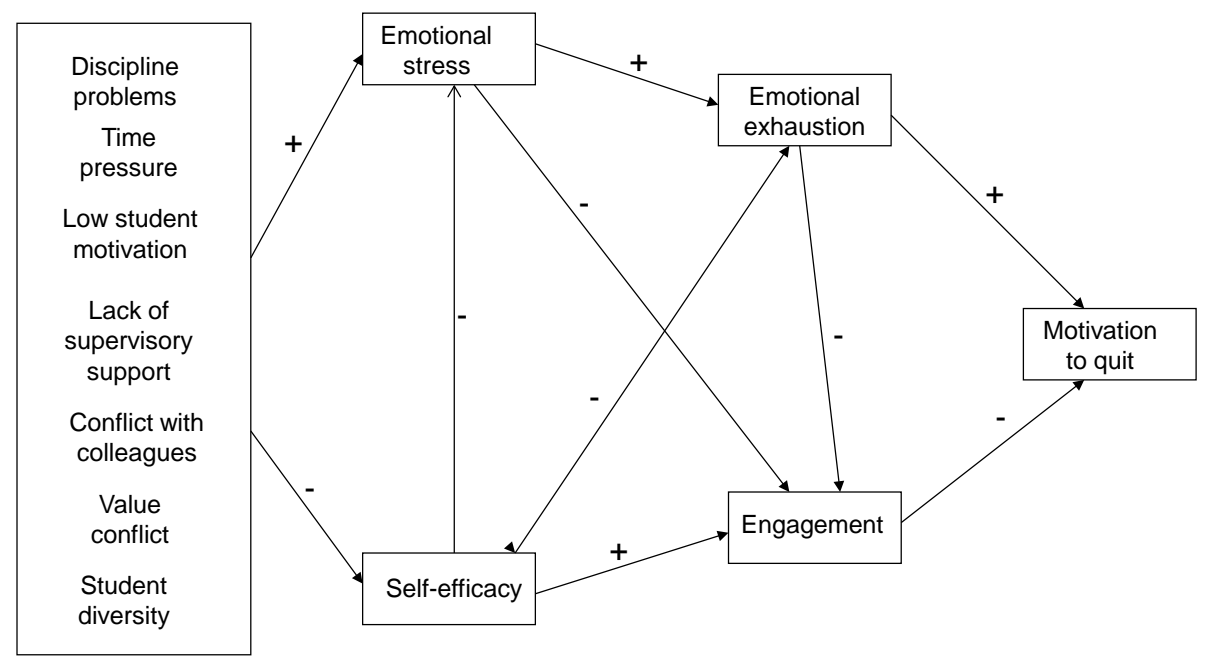

Figure 1. Theoretical model of relations between the study variables.

\section{Method}

\subsection{Norwegian Senior High School}

Senior high school in Norway starts the year the students are 16 years of age and is a three year education from grade 11 to 13. It is voluntary but 92 percent of the population enters senior high school (Statistics Norway, 2016). The dropout rate has been high the last years - 29 percent of the students do not graduate within five years (Statistics Norway, 2015).

\subsection{Participants and Procedure}

A total of 523 teachers from nine senior high schools participated in this study. The nine schools were drawn by random from all senior high schools in three counties in central Norway. The schools ranged from small schools with 30 - 40 teachers to larger schools with more than 100 teachers. Participation was voluntary both for the schools and the individual teachers. All schools we asked agreed to participate. A particular period of time during working hours was set aside for all teachers to fill out the questionnaire at the same time. When the questionnaires were filled out they were put in envelopes and sealed at the spot in order to assure the teachers that they were anonymous. We distributed 645 questionnaires and received 523. Thus, 81 percent of the teachers working full time participated in the study. Forty-two present of the participants were females whereas 58\% were males. The age of the participants ranged from 23 years to 66 years with a mean age of 47.3 years. The experience as a teacher ranged from one to 44 years with a mean of 15.6 .

\subsection{Instruments}

\subsubsection{Discipline Problems}

Discipline problems were measured by a three-item scale previously tested by Skaalvik and Skaalvik (2011a). The items were: "My teaching is often disrupted by students who lack discipline," "Some students with behavioral problems make it difficult to carry out lessons as planned," and "Controlling students' behavior takes a lot of time and effort". Responses were given on a 6-point scale from "Completely disagree" (1) to "Completely agree” (6). Skaalvik and Skaalvik (2011a) reported a Cronbach's alpha of .87 whereas we found an alpha value of .83 in the present study.

\subsubsection{Student Diversity}

A three-item scale measuring teachers' perception of student diversity was developed for the purpose of the present study. Student diversity was defined as variation in abilities among students in the same class. Because about 90 percent of the student population enters senior high schools we expected a large variation in abilities. The items measuring student diversity were: "In my classes there are large variations in students' abilities," "In 
my classes there are large variations in students' needs," and "In my classes there is a huge difference between the best and the poorest students." Responses were given on a 6-point scale from "Completely disagree" (1) to "Completely agree" (6). Cronbach’s alpha for the scale was .90.

\subsubsection{Time Pressure}

Time pressure was measured by a five-item scale. Three of the items are previously tested with a Cronbach's alpha of .81 (Skaalvik \& Skaalvik, 2011a). These items were: "Preparation for teaching must often be done after working hours," "Life at school is hectic and there is no time for rest and recovery", and "Meetings, administrative work, and documentation take much of the time that should be used for teaching preparation." The two additional items were: "Teachers are loaded with work," and "To provide a good education teachers would need more time with the students and for preparing their teaching." Responses were given on a 6-point scale from "Completely disagree" (1) to "Completely agree" (6). Cronbach’s alpha for the five-item scale was .83.

\subsubsection{Poor Student Motivation}

Not only discipline problems but also poor student motivation has been reported as potential stressors in school (see above). The teachers' perceptions of poor student motivation were measured by a four-item scale developed for the purpose of this study. The items were: "Many of my students show little interest in schoolwork," "Many of my students give up once they meet a challenge," "I find it difficult to make all students work seriously with schoolwork," and "Many of my students show little effort at schoolwork." Responses were given on a 6-point scale from "Completely disagree" (1) to "Completely agree" (6). Cronbach’s alpha for the scale was .89.

\subsubsection{Conflict with Colleagues}

Positive relations with colleagues have been shown to positively predict job satisfaction and to work as a buffer against burnout (e.g., Skaalvik \& Skaalvik, 2011a; Pines \& Aronson, 1988). In this study we measured lack of support, negative relations, and conflicts with colleagues. Conflicts with colleagues were measured by three items developed for the purpose of this study: "Even if I should need it I cannot expect any support from my colleagues," "I have a tense relation to my colleagues," and "I often have conflicts with my colleagues." Responses were given on a 6-point scale from "Completely disagree” (1) to "Completely agree” (6). Cronbach’s alpha for the scale was .79.

\subsubsection{Lack of Supervisory Support and Trust}

Lack of supervisory support and trust were measured by a four-item scale. The scale was a modified and extended version of a scale measuring supervisory support (Skaalvik \& Skaalvik, 2011a). The items were: "My relationship with my supervisors is characterized by a lack of trust and respect," "I have a tense relation to my supervisors," "In educational matters, it serves no purpose to seek help and advice from my supervisors," and "If I have problems with the students I meet little understanding and support from my supervisors." Responses were given on a 6-point scale from "Completely disagree" (1) to "Completely agree" (6). Cronbach's alpha for the scale was .77.

\subsubsection{Value Conflict}

According to Sahlberg (2010) teachers are often driven by values. However, teachers may have different goals, values, and beliefs. As pointed out by Skaalvik and Skaalvik (2011a, 2011b) teachers may differ in their beliefs about what goals should be pursued, what content should be emphasized, and what educational means and methods should be used. Furthermore, Skaalvik and Skaalvik (2011a) suggest that a teacher who feels that the prevailing goals and values at the school are incompatible with her or his personal goals and values, which we term value conflict, may experience what Rosenberg $(1977,1979)$ referred to as contextual dissonance, which may result in a feeling of not belonging, a feeling that one does not fit (Rosenberg, 1977, 1979). Whereas Skaalvik and Skaalvik (2011a) found that a high value consonance positively predicted teachers feeling of belonging we expected value conflict to predict higher levels of emotional stress and lower levels of self-efficacy. Value conflict was in this study measured by a three-item scale which was modified from the value consonance scale used by Skaalvik and Skaalvik (2011a). The items were: "The goals and values which are emphasized at this school do not fit my personal educational values," "My colleagues and I have quite different opinions about what is important in education," and "My colleagues and I have quite different opinions about what constitutes good 
teaching and education.” Responses were given on a 6-point scale from "Completely disagree” (1) to "Completely agree" (6). Cronbach's alpha for the scale was .77.

\subsubsection{Emotional Stress}

Emotional stress was defined as the experience by a teacher of unpleasant emotions resulting from aspects of the work as a teacher (se Teacher stress). It was measured by a five-item scale developed for the purpose of this study. The items did not refer to any particular school contexts or stressors in order to discriminate between possible sources of stress and the resultant experience of stress. The items were: "I experience a lot of stress in my work," "I am often anxious when going to work," "Working as a teacher is extremely stressful," "I often worry that I shall not manage my job," and "A teacher always has to be on alert." Responses were given on a 6-point scale from "Completely disagree” (1) to "Completely agree” (6). Cronbach’s alpha for the scale was .79.

\subsubsection{Teacher Self-Efficacy}

Teacher self-efficacy was measured by a multidimensional 24-item Norwegian Teacher Self-Efficacy Scale (NTSES; Skaalvik \& Skaalvik, 2007; Skaalvik \& Skaalvik, 2010). The scale has six dimensions measured by four items each. The dimensions are self-efficacy for: instruction, adapting education to individual students' needs, motivating students, keeping discipline, cooperating with colleagues and parents, and coping with changes and challenges. An example of an item is "How certain are you that you can wake the desire to learn even among the lowest achieving students?" (motivating students). Responses were given on a 7-point scale from "Not certain at all" (1) to "Absolutely certain" (7). The scale shows good validity both in Norway and Italy (Avanzi, Miglioretti, Velasco et al., 2013). The scale was originally developed for use in elementary school and middle school and is not previously tested in senior high school. Because teachers in senior high school have less contact with parents the dimension "cooperating with colleagues and parents" were changed into "cooperating with colleagues". The original scale is displayed elsewhere (Skaalvik, 2007; Skaalvik \& Skaalvik, 2010). Cronbach’s alpha for the scale was .92 whereas alphas for the six subscales were $.86, .91, .93, .92, .82$, and .83 respectively.

\subsubsection{Engagement}

Engagement for teaching was measured by the Utrecht Work Engagement Scale (UWES; Schaufeli \& Bakker, 2004). The scale has three dimensions of work engagement: vigor, dedication, and absorption. Vigor is characterized by high levels of energy and mental strength whereas dedication refers to experiencing enthusiasm, inspiration, pride, and challenge. Absorption refers to being concentrated and involved in one's own work. We used the short 9-item version of the scale (Schaufeli \& Bakker, 2010) which is previously tested on Norwegian elementary and middle school teachers (Skaalvik \& Skaalvik, 2013). An example of an item is "At my work, I feel bursting with energy" (Vigor). Responses were given on a 7-point scale from "Never" (0) to "Every day" (6). In the present study the scale had a Cronbachs' alpha of .89.

\subsubsection{Motivation to Leave the Teaching Profession (Quit)}

The teachers' motivation to leave the teaching profession was measured by a 3-item motivation to leave scale (Skaalvik \& Skaalvik, 2011a). The items were: "I wish I had a different job to being a teacher", "If I could choose over again I would not be a teacher" and "I often think of leaving the teaching profession". Responses were given on a 6-point scale from "Completely disagree” (1) to "Completely agree” (6). Cronbach’s alpha for the scale was .90 .

\subsection{Data Analysis}

We first estimated zero order correlations between the study variables. We then conducted a confirmatory factor analysis of the seven stressors to ensure that they were separate but correlated variables. Lastly we tested the theoretical model by means of structural equation modeling (SEM analysis) using the Amos 23 program.

\section{Results}

\subsection{Zero Order Correlations}

Table 1 shows zero order correlations among the study variables. Looking first at the school context variables 
Table 1. Zero order correlations and descriptive statistics.

\begin{tabular}{|c|c|c|c|c|c|c|c|c|c|c|c|c|}
\hline Study variables & 1 & 2 & 3 & 4 & 5 & 6 & 7 & 8 & 9 & 10 & 11 & 12 \\
\hline 1) Discipline problems & --- & .41 & .25 & .45 & .09 & -.02 & .03 & .29 & -.09 & .26 & -.1 & .17 \\
\hline 2) Diversity & & --- & .24 & .36 & .01 & -.03 & .01 & .22 & -.07 & .16 & .01 & .12 \\
\hline 3) Time pressure & & & --- & .23 & .01 & .14 & -.02 & .61 & -.11 & .58 & -.11 & .18 \\
\hline 4) Low student motivation & & & & --- & .11 & .1 & .15 & .31 & -.27 & .29 & -.27 & .29 \\
\hline 5) Conflicts with colleagues & & & & & --- & .31 & .41 & .12 & -.11 & .15 & -.19 & .19 \\
\hline 6) Lack of supervisory support & & & & & & --- & .41 & .14 & -.25 & .23 & -.25 & .24 \\
\hline 7) Value conflicts & & & & & & & --- & .11 & -.27 & .12 & -.23 & .21 \\
\hline 8) Emotional stress & & & & & & & & --- & -.28 & .72 & -.3 & .38 \\
\hline 9) Self-efficacy & & & & & & & & & --- & -.28 & .51 & -.31 \\
\hline 10) Emotional exhaustion & & & & & & & & & & --- & -.43 & .46 \\
\hline 11) Engagement & & & & & & & & & & & --- & -.52 \\
\hline 12) Motivation to quit & & & & & & & & & & & & --- \\
\hline M & 8.2 & 14.7 & 19.5 & 13.1 & 2.8 & 7.3 & 5.3 & 17.6 & 117.5 & 17 & 51.1 & 6.4 \\
\hline SD & 3.6 & 3.2 & 3.5 & 4.9 & 1.4 & 3.9 & 2.3 & 4.8 & 15.1 & 7.1 & 8.6 & 3.6 \\
\hline
\end{tabular}

Note. All correlations higher than .08 are significant $(p<.05)$.

(potential stressors) the most striking result is that most of these correlations are weak and close to zero. However, there are a few moderate correlations ranging from $r=.31$ to $r=.45$. Discipline problems are moderately correlated with student diversity $(r=.41)$ and time pressure $(r=.45)$. A possible interpretation is that discipline problems increases in classes with high student diversity and that it causes time pressure because dealing with discipline problems is time consuming. Value conflicts, that the prevailing educational goals and values at the school are not compatible with the teachers' personal goals and values, are moderately correlated with both conflict with colleagues and lack of supervisory support ( $r=.41$ for both). These results support the notion that teachers are driven by values and that cooperation between teachers with different educational goals and values may constitute a challenge. The low correlations between the school-context variables indicate that there is no serious covariance problem in conducting structural analysis (see below).

The zero order correlations between the outcome variables-emotional stress, teaching self-efficacy, emotional exhaustion, engagement in teaching, and motivation to quit-ranged from moderate to strong. The strongest correlation was found between emotional stress and emotional exhaustion $(r=.72)$. The strongest correlations with motivation to quit were found for engagement $(r=-.52)$ and emotional exhaustion $(r=.46)$.

\subsection{Confirmatory Factor Analysis}

To make sure that the seven potential stressors could be treated as separate but correlated exogenous variables we first conducted a confirmatory factor analysis defining seven primary factors: discipline problems, time pressure, low student motivation, lack of supervisory support, conflict with colleagues, value conflict, and student diversity. None of the error variances in the measurement model were allowed to correlate. The model had good fit to the data $\left(\chi^{2}(254, N=523)=554.711, p<.001, \mathrm{CMIN} / \mathrm{DF}=2.148, \mathrm{RMSEA}=.048\right.$, IFI $=.950$, TLI $=.935$, and CFI $=.949$ ) and all regression weights in the model were significant at $p<.001$. We also tested the measurement model for self-efficacy by means of structural equation modeling defining six factors corresponding to the six dimensions in the scale. The model is previously tested (Skaalvik, 2007; Skaalvik \& Skaalvik, $2010)$ but not for teachers in senior high school. The model had good fit to the data $\left(\chi^{2}(237, N=523)=647.656\right.$, $p<.001, \mathrm{CMIN} / \mathrm{DF}=2.733$, RMSEA $=.058, \mathrm{IFI}=.950, \mathrm{TLI}=.936$, and CFI $=.949)$ and all regression weights in the model were significant at $p<.001$. 


\subsection{Structural Equation Modeling}

The relations between the variables were further investigated by means of structural equation modeling testing the theoretical model displayed in Figure 1. The SEM model defined the seven potential stressors as exogenous variables. We deleted non-significant paths one by one starting with the path with the lowest regression weight. The final empirical model, showing standardized regression weights, is displayed in Figure 2. Three of the potential stressors were, in the model context, not significantly related to any of the endogenous variables. For simplicity, these variables - conflict with colleagues, discipline problems, and student diversity—are not included in Figure 2. The model had acceptable fit to the data $\left(\chi^{2}(954, N=523)=2206.751, p<.001\right.$, CMIN/DF $=2.313, \mathrm{RMSEA}=.050, \mathrm{IFI}=.905, \mathrm{TLI}=.891$, and CFI $=.904)$. Indirect and total effects are shown in Table 2.

Time pressure predicted emotional stress very strongly $(\beta=.76)$. None of the reminding stressors were directly related to emotional stress when controlled for the effect of time pressure. Teacher self-efficacy was negatively associated with value conflict $(\beta=-.15)$, lack of supervisory support $(\beta=-.19)$, and low student motivation $(\beta=-.31)$. Also, these three potential stressors were indirectly but weakly associated with emotional stress (Table 2). The indirect relations were mediated through teacher self-efficacy.

Teachers' feeling of exhaustion was positively and strongly associated with emotional stress $(\beta=.69)$. It was also negatively associated with teacher self-efficacy. The negative association was mediated through emotional stress (Table 2). Engagement was positively and strongly related to self-efficacy $(\beta=.51)$ and negatively and moderately related to exhaustion ( $\beta=-.33$ ). Motivation to leave the teaching profession was negatively related to engagement $(\beta=-.45)$ and positively related to exhaustion $(\beta=.33)$.

None of the potential stressors were directly related to engagement. Also, only low student motivation and lack of supervisory support were directly but weakly related to exhaustion ( $\beta=.10$ and .18 , respectively) and only low student motivation was directly but weakly related to teachers' motivation to leave the teaching profession $(\beta=.13)$. However, Figure 2 and Table 2 reveal indirect associations between four of the potential stressors and exhaustion, engagement and motivation to leave the teaching profession. Time pressure was indirectly and strongly related to exhaustion (standardized indirect effect $=.529$ ) and moderately related to both engagement (standardized indirect effect $=-.176$ ) and motivation to quit (standardized indirect effect $=.15$ ). Also, engagement was indirectly and negatively related to value conflict (standardized indirect effect $=-.083$ ), lack of supervisory support (standardized indirect effect $=-.163$ ), and low student motivation (standardized indirect effect $=-.206)$.

\subsection{Gender Differences}

To explore gender differences we tested differences in statistical means between male and female teachers by

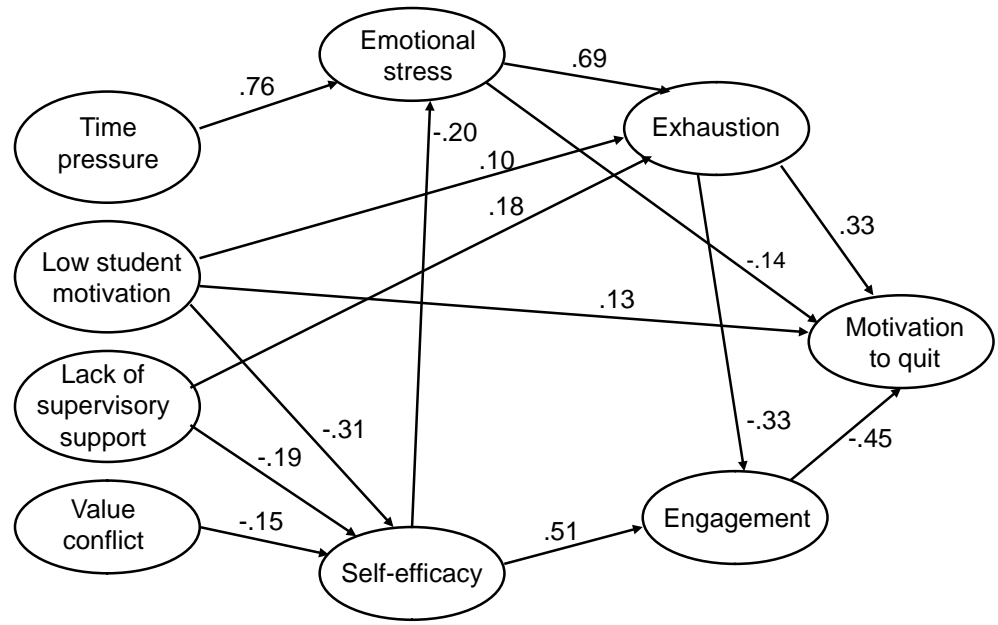

Figure 2. Structural model of relations between workplace stressors, teacher self-efficacy, emotional stress, exhaustion, engagement, and motivation to leave the teaching profession (quit). 
Table 2. Indirect and total effects on emotional stress, exhaustion, engagement, and motivation to quit.

\begin{tabular}{|c|c|c|}
\hline Latent variables & $\begin{array}{l}\text { Standardized } \\
\text { indirect effects }\end{array}$ & $\begin{array}{l}\text { Standardized } \\
\text { total effects }\end{array}$ \\
\hline \multicolumn{3}{|l|}{ Emotional stress } \\
\hline Low student motivation & .060 & .061 \\
\hline Lack of supervisory support & .037 & .037 \\
\hline Value conflicts & .030 & .030 \\
\hline \multicolumn{3}{|l|}{ Emotional exhaustion } \\
\hline Time pressure & .529 & .529 \\
\hline Low student motivation & .043 & .146 \\
\hline Lack of supervisory support & .025 & .207 \\
\hline Value conflicts & .021 & .021 \\
\hline Self-efficacy & -.136 & -.136 \\
\hline \multicolumn{3}{|l|}{ Engagement } \\
\hline Time pressure & -.176 & -.176 \\
\hline Low student motivation & -.206 & -.206 \\
\hline Lack of supervisory support & -.163 & -.163 \\
\hline Value conflicts & -.083 & -.083 \\
\hline Self-efficacy & .045 & .551 \\
\hline Emotional stress & -.232 & -.232 \\
\hline \multicolumn{3}{|l|}{ Motivation to quit } \\
\hline Time pressure & .150 & .150 \\
\hline Low student motivation & .132 & .258 \\
\hline Lack of supervisory support & .136 & .136 \\
\hline Value conflicts & .040 & .040 \\
\hline Self-efficacy & -.266 & -.266 \\
\hline Emotional stress & .332 & .197 \\
\hline Emotional exhaustion & .150 & .479 \\
\hline
\end{tabular}

independent samples t-test. We also used Cohen's $d$ to estimate effect size. Cohen's $d$ is a measure of the difference in statistical means between two groups in terms of standard deviation. According to Cohen (1988) a difference that is lower than .2 standard deviation is considered not to be significant. A difference between .2 and .5 standard deviations is considered significant, but small whereas a difference larger than .8 standard deviation is considered large. For a difference to be considered significant we required both $p<.05$ and $d>.19$.

Our analysis revealed few and small gender differences (Table 3). We found significant gender differences for two of the seven potential stressors. Female teachers experienced stronger time pressure compared to male teachers ( $p<.001, d=.46$ ) whereas male teachers reported higher levels of value conflict than female teachers $(p<.01, d=.28)$. We also found significant gender differences for two of the outcome variables. Female teachers both reported higher levels of emotional stress $(p<.001, d=.54)$ and higher levels of emotional exhaustion $(p<.01, d=.27)$ compared to male teachers. 
Table 3. Statistical means for male and female teachers.

\begin{tabular}{cccccc}
\hline Study variables & Males & Females & $\mathrm{t}$ & $p$ & Effect size \\
\hline Time pressure & 18.57 & 20.17 & 5.25 & $<.001$ & .46 \\
Low student motivation & 12.99 & 13.05 & .14 & $>.05$ & .01 \\
Lack of supervisory support & 7.32 & 7.34 & .1 & $>.05$ & .01 \\
Value conflicts & 5.71 & 5.06 & -3.1 & $<.01$ & .28 \\
Conflicts with colleagues & 2.85 & 2.75 & -.79 & $>.05$ & .07 \\
Student diversity & 14.45 & 14.81 & 1.24 & $>.05$ & .11 \\
Discipline problems & 8.04 & 8.21 & .55 & $>.05$ & .05 \\
Self-efficacy & 118.85 & 116.64 & -1.61 & $>.05$ & .14 \\
Emotional stress & 15.84 & 18.46 & 6.24 & $<.001$ & .54 \\
Emotional exhaustion & 15.87 & 17.8 & 3.1 & $<.01$ & .27 \\
Engagement & 50.51 & 51.71 & 1.53 & $>.05$ & .14 \\
Motivation to quit & 6.61 & 6.27 & -1.07 & $>.05$ & .1 \\
\hline
\end{tabular}

Note. Equal variances not assumed for estimation of t. Effect size $<.20$ is regarded as not significant, effect size between .20 and .49 is regarded to be significant but small, effect size between .50 and .79 is regarded to be significant and moderate, and effect size $>.80$ is regarded to be large.

\section{Discussion}

In this study, we measured senior high school teachers' perception of seven potential stressors (or potentially stressful working conditions) at school. The potential stressors were: discipline problems, time pressure, low student motivation, conflict with colleagues, lack of supervisory support, value conflict, and student diversity. These potential stressors were chosen because they are found to increase stress-related outcomes in previous research. The correlations among the seven potential stressors were weak to moderate. A possible interpretation of this finding is that one source of stress does not necessarily generalize into other sources of stress and that each source of stress should to be addressed separately in order to reduce teacher stress.

The SEM analysis revealed that only four of the seven potential stressors-time pressure, low student motivation, lack of supervisory support, and value conflict—were significantly associated with the outcome variables. Time pressure or workload strongly predicted emotional stress. Also, time pressure was the only out of seven potential stressors that in the SEM model was directly and significantly related to emotional stress. The items measuring emotional stress refer generally to stress, stressful conditions, being on alert, and being anxious. Therefore, it is unlikely that the finding that time pressure was the only predictor of emotional stress was caused by the way we measured emotional stress.

Both previous international research and research among Norwegian teachers confirm that time pressure is an important source of stress which predicts emotional exhaustion and burnout (e.g., Kokkinos, 2007; Skaalvik \& Skaalvik, 2011a). The present study supports these results. However, the analysis also reveals that the association between time pressure and exhaustion is an indirect one, mediated through a general experience of emotional stress. Emotional exhaustion was in turn associated both with lower levels of engagement and stronger motivation to leave the profession (see also Skaalvik \& Skaalvik, 2011a). This finding underscores the importance of discriminating between the prevalence of potential stressors in the school environment and teachers general experiences of emotional stress.

The SEM analysis revealed that time pressure was not significantly related to teachers' self-efficacy. This result is in accordance with previous findings by Betoret and Artiga (2010). These researchers found that workload was unrelated to instructional self-efficacy and very weakly related to management self-efficacy $(r=-.13)$. Taken together, these findings indicate that a heavy workload does not reduce the teachers' expectations of being able to carry out the tasks, but that the workload and the possible experience of not having the time to do all tasks properly may lead to emotional stress. 
Three of the potential stressors—-value conflict, low student motivation, and lack of supervisory supportwere negatively related to teacher self-efficacy. These school context variables explained 21 percent of the variance in teacher self-efficacy, which again was a strong predictor of engagement. Value consonance-the feeling that the prevailing goals and values at the school are in accordance with the teachers' personal values-have in previous research been shown to predict teachers feeling of belonging and job satisfaction (Skaalvik \& Skaalvik, 2011a, 2011b). The importance of value consonance was in the present study supported in that value conflict - the feeling that the prevailing goals and values at the school are not in accordance with the teachers' personal values-negatively predicted self-efficacy directly and engagement indirectly. Lack of supervisory support also predicted teacher self-efficacy negatively. This is in accordance with social cognitive theory in which verbal persuasion is viewed as one source of self-efficacy (Bandura, 1997). Low student motivation also predicted teacher self-efficacy negatively. A possible interpretation is that motivating the students is seen as an important part of the instructional process. Therefore, experiencing students to be unmotivated may be interpreted as a personal failure to motivate students for schoolwork, which may lead to a lack of self-efficacy for teaching.

Three of the potential stressors-discipline problems, student diversity, and conflict with colleagues—were in the SEM model unrelated to all outcome variables and are therefore not included in Figure 2. The finding that discipline problems were unrelated to the outcome variables were particularly surprising because previous research show that disruptive student behavior is predictive of overall job stress and emotional exhaustion as well as lower levels of commitment and teacher self-efficacy (Betoret \& Artiga, 2010; Collie et al., 2012; Fernet et al., 2012; Klassen \& Chiu, 2010, 2011; Skaalvik \& Skaalvik, 2011a). However, all these previous studies either involved elementary and middle school teachers only or teachers from a mixture of school levels with a majority of elementary and middle school teachers. In the present study, both the zero-order correlations and the SEM analysis indicated that student lack of motivation was a more powerful predictor of the outcome variables than disruptive student behavior. A possible explanation of this finding may be low student motivation in Norwegian senior high school manifest itself in other ways than disruptive behavior, for instance by students paying less attention, showing lack of involvement, and not doing their homework or assignments at school. Such behavior may not be perceived as discipline problems by the teachers. However, this is merely a speculation that needs to be examined in future research.

Two recent interview studies also identified student diversity as an important stressor among elementary and middle school teachers (Shernoff et al., 2011; Skaalvik \& Skaalvik, 2015). Moreover, in a study of elementary and secondary school teachers Betoret (2009) found that student diversity predicted teacher self-efficacy negatively and emotional exhaustion positively. However, in the study by Betoret (2009) student diversity was not entered as a separate variable in SEM analysis. Student diversity was in the present study positively but weakly correlated with emotional stress, exhaustion, and motivation to quit but not significantly related to these variables when controlled for other potential stressors in the SEM analysis. A possible explanation is that student diversity was positively correlated with time pressure and lack of student motivation. Another possible interpretation may be that the emphasis on adapting teaching to individual student's needs and abilities traditionally has been greater in elementary school and middle school than in senior high school which is not compulsory. Therefore, student diversity may be experienced as more demanding and stressful in elementary school and middle school than in senior high school.

Positive relations with colleagues is in previous research in elementary school and middle school shown to be positively related to belonging and job satisfaction and negatively related to emotional exhaustion (Droogenbroeck, Spruyt, \& Vanroelen, 2014; Skaalvik \& Skaalvik, 2011; Zembylas \& Papanastasiou, 2006). In the present study, the SEM analysis showed that negative relations and conflicts with did not relate significantly to any of the outcome variables. A possible explanation is that teachers in elementary school and middle school often work in teacher teams whereas teamwork is less practiced in senior high school in Norway. Therefore, work-related stress and teacher self-efficacy may be less dependent on relations with colleagues in senior high school than in elementary school.

Interestingly, only one of the potential stressors was directly related to teachers' motivation to leave the profession. Low student motivation was directly but weakly associated with motivation to quit. Thus, the school context variables, which we term potential stressors, seem to affect teachers' motivation to quit indirectly, through emotional exhaustion and engagement. The SEM model indicated two main routes to teachers' motivation to leave the profession: 1 ) one route from time pressure via emotional stress and exhaustion to motivation to quit and 2) another route from lack of supervisory support and trust, low student motivation and value conflicts 
via lower self-efficacy and lower engagement to motivation to quit.

This study has both important theoretical and practical implications. Theoretically, the findings imply that different potential stressors in school affect teachers' motivation for teaching through different psychological processes. We suggest that some stressors-in this study time pressure-affect teachers' motivation through stress responses and emotional exhaustion whereas other stressors affect teachers' motivation through lower self-efficacy and lower engagement. A practical implication that may be drawn both from this study is the urgent need to reduce the time pressure in the teacher profession. One measure to reduce the time pressure may be to reduce the number of teaching hours or the number of students in each class. Whereas these measures have great economic implications other measures are less dependent on economy. Such measures include working to establish shared goals and values at school, which may also result in more positive relations between the teachers and between the teachers and the school administration.

This study has several limitations. We only included seven potential stressors in the study. Although the potential stressors were chosen because they have been highlighted in previous studies, future research should also explore alternative stressors. Moreover, this study was designed as a cross sectional investigation and longitudinal studies are highly needed. Also, the participants in this study were teachers in senior high school and similar studies need to be conducted including elementary and middle school teachers.

\section{References}

Avanzi, L., Miglioretti, M., Velasco, V., Balducci, C., Vecchio, L., Fraccaroli, F., \& Skaalvik, E. M. (2013). Cross-Validation of the Norwegian Teacher's Self-Efficacy Scale (NTSES). Teaching and Teacher Education, 31, 69-78. http://dx.doi.org/10.1016/j.tate.2013.01.002

Bakker, A. B., \& Bal, P. M. (2010). Weekly Work Engagement and Performance: A Study among Starting Teachers. Journal of Occupational and Organizational Psychology, 83, 189-206. http://dx.doi.org/10.1348/096317909X402596

Bandura, A. (1977). Self-Efficacy—Toward a Unifying Theory of Behavioral Change. Psychological Review, 84, $191-215$. http://dx.doi.org/10.1037/0033-295X.84.2.191

Bandura, A. (1997). Self-Efficacy: The Exercise of Control. New York: Freeman.

Bandura, A. (2006). Adolescent Development from an Agentic Perspective. In F. Pajares, \& T. Urdan (Eds.), Self-Efficacy Beliefs of Adolescents (pp. 1-43). Greenwich, Connecticut: Information Age Publishing.

Betoret, F. D. (2006). Stressors, Self-Efficacy, Coping Resources, and Burnout among Secondary School Teachers in Spain. Educational Psychology: An International Journal of Experimental Educational Psychology, 26, 519-539.

http://dx.doi.org/10.1080/01443410500342492

Betoret, F. D. (2009). Self-Efficacy, School Resources, Job Stressors and Burnout among Spanish Primary and Secondary School Teachers: A Structural Equation Approach. Educational Psychology, 29, 45-68. http://dx.doi.org/10.1080/01443410802459234

Bong, M., \& Skaalvik, E. M. (2003). Academic Self-Concept and Self-Efficacy: How Different Are They Really? Educational Psychology Review, 15, 1-40. http://dx.doi.org/10.1023/A:1021302408382

Brouwers, A., \& Tomic, W. (2000). A Longitudinal Study of Teacher Burnout and Perceived Self-Efficacy in Classroom Management. Teaching and Teacher Education, 16, 239-253. http://dx.doi.org/10.1016/S0742-051X(99)00057-8

Chan, D. (2002). Stress, Self-Efficacy, Social Support and Psychological Distress among Prospective Teachers in Hong Kong. Educational Psychology, 22, 557-570. http://dx.doi.org/10.1080/0144341022000023635

Collie, R. J., Shapka, J. D., \& Perry, N. E. (2012). School Climate and Social-Emotional Learning: Predicting Teacher Stress, Job Satisfaction, and Teaching Efficacy. Journal of Educational Psychology, 104, 1189-1204. http://dx.doi.org/10.1037/a0029356

Droogenbroeck, F. V., Spruyt, B., \& Vanroelen, C. (2014). Burnout among Senior Teachers: Investigating the Role of Workload and Interpersonal Relationships at Work. Teaching and Teacher Education, 43, 99-109.

http://dx.doi.org/10.1016/j.tate.2014.07.005

Fernet, C., Guay, F., Senécal, C., \& Austin, S. (2012). Predicting Intraindividual Changes in Teacher Burnout: The Role of Perceived School Environment and Motivational Factors. Teaching and Teacher Education, 28, 514-525. http://dx.doi.org/10.1016/j.tate.2011.11.013

Friedman, I. A. (1995). Student Behavior Patterns Contributing to Teacher Burnout. Journal of Educational Research, 88, 281-333. http://dx.doi.org/10.1080/00220671.1995.9941312

Gilbert, R. B., Adesope, O. O., \& Schroeder, N. L. (2014). Efficacy Beliefs, Job Satisfaction, Stress and Their Influence on the Occupational Commitment of English-Medium Content Teachers in the Dominican Republic. Educational Psychology, 
34, 876-899. http://dx.doi.org/10.1080/01443410.2013.814193

Hakanen, J. J., Bakker, A. B., \& Schaufeli, W. B. (2006). Burnout and Work Engagement among Teachers. Journal of School Psychology, 43, 495-513. http://dx.doi.org/10.1016/j.jsp.2005.11.001

Helms-Lorenz, M., Slof, B., Vermue, C. E., \& Canrinus, E. T. (2011). Beginning Teachers' Self-Efficacy and Stress and the Supposed Effects of Induction Arrangements. Educational Studies, 38, 189-207. http://dx.doi.org/10.1080/03055698.2011.598679

Hong, J. Y. (2012). Why Do Some Beginning Teachers Leave the School, and Others Stay? Understanding Teacher Resilience through Psychological Lenses. Teachers and Teaching: Theory and Practice, 18, 417-440. http://dx.doi.org/10.1080/13540602.2012.696044

Ingersoll, R. M. (2001). Teacher Turnover and Teacher Shortages: An Organizational Analysis. American Educational Research Journal, 38, 499-531. http://dx.doi.org/10.3102/00028312038003499

Johnson, S., Cooper, C., Cartwright, S., Donald, I., Taylor, P., \& Millet, C. (2005). The Experience of Work-Related Stress across Occupations. Journal of Managerial Psychology, 20, 178-187. http://dx.doi.org/10.1108/02683940510579803

Klassen, R., \& Chiu, M. M. (2010). Effects of Teachers’ Self-Efficacy and Job Satisfaction: Teacher Gender, Years of Experience, and Job Stress. Journal of Educational Psychology, 102, 741-756. http://dx.doi.org/10.1037/a0019237

Klassen, R., \& Chiu, M. M. (2011). The Occupational Commitment and Intention to Quit of Practicing and Pre-Service Teachers: Influence of Self-Efficacy, Job Stress, and Teaching Context. Contemporary Educational Psychology, 36, 114129. http://dx.doi.org/10.1016/j.cedpsych.2011.01.002

Klassen, R., Wilson, E., Siu, A. F. Y., Hannok, W., Wong, M. W., Wongsri, N., Sonthisap, P., Pibulchol, C., Buranachaitavee, Y., \& Jansem, A. (2013). Preservice Teachers' Work Stress, Self-Efficacy, and Occupational Commitment in Four Countries. European Journal of Psychology of Education, 28, 1289-1309. http://dx.doi.org/10.1007/s10212-012-0166-X

Kokkinos, C. M. (2007). Job Stressors, Personality and Burnout in Primary School Teachers. British Journal of Educational Psychology, 77, 229-243. http://dx.doi.org/10.1348/000709905X90344

Kyriacou, C. (1987). Teacher Stress and Burnout: An International Review. Educational Research, 29, 146-152. http://dx.doi.org/10.1080/0013188870290207

Kyriacou, C. (2001). Teacher Stress: Directions for Future Research. Educational Review, 53, 27-35. http://dx.doi.org/10.1080/00131910120033628

Liu, S., \& Onwuegbuzie, A. J. (2012). Chinese Teachers’ Work Stress and Their Turnover Intention. International Journal of Educational Research, 53, 160-170. http://dx.doi.org/10.1016/j.ijer.2012.03.006

Maslach, C., Jackson, S. E., \& Leiter, M. P. (1996). Maslach Burnout Inventory Manual (3rd ed.). Mountain View, CA: CPP, Inc.

Montgomery, C., \& Rupp, A. A. (2005). Meta-Analysis for Exploring the Diversity Causes and Effects of Stress in Teachers. Canadian Journal of Education, 28, 458-486. http://dx.doi.org/10.2307/4126479

Pines, A., \& Aronson, E. (1988). Career Burnout. Causes and Cures. New York: The Free Press.

Rosenberg, M. (1977). Contextual Dissonance Effects: Nature and Causes. Psychiatry, 40, 205-217.

Rosenberg, M. (1979). Conceiving the Self. New York: Basic Books.

Sahlberg, P. (2010). Rethinking Accountability in a Knowledge Society. Journal of Educational Change, 11, 45-61. http://dx.doi.org/10.1007/s10833-008-9098-2

Saricam, H., \& Sakiz, H. (2014). Burnout and Teachers Self-Efficacy among Teachers Working in Special Education in Turkey. Educational Studies, 40, 423-437. http://dx.doi.org/10.1080/03055698.2014.930340

Schaufeli, W. B., \& Bakker, A. D. B. (2004). Job Demands, Job Resources, and Their Relationship with Burnout and Engagement: A Multisample Study. Journal of Organizational Behavior, 25, 293-315. http://dx.doi.org/10.1002/job.248

Schunk, D. H., \& Meece, J. L. (2006). Self-Efficacy Development in Adolescence. In F. Pajares, \& T. Urdan (Eds.), Self-Efficacy Beliefs of Adolescents (pp. 71-96). Greenwich, CT: Information Age Publishing.

Schwarzer, R., \& Hallum, S. (2008). Perceived Teacher Self-Efficacy as a Predictor of Job Stress and Burnout: Mediation Analysis. Applied Psychology, 57, 152-171. http://dx.doi.org/10.1111/j.1464-0597.2008.00359.X

Shernoff, E. S., Mehta, T. G., Atkins, M. S., Torf, R., \& Spencer, J. (2011). A Qualitative Study of the Sources and Impact of Stress among Urban Teachers. School Mental Health, 3, 59-69. http://dx.doi.org/10.1007/s12310-011-9051-z

Skaalvik, E. M. (1997). Self-Enhancing and Self-Defeating Ego-Orientation: Relations with Task and Avoidance Orientation, Achievement, Self-Perceptions, and Anxiety. Journal of Educational Psychology, 89, 71-81.

http://psycnet.apa.org/doi/10.1037/0022-0663.89.1.71 http://dx.doi.org/10.1037/0022-0663.89.1.71

Skaalvik, E. M., \& Skaalvik, S. (2007). Dimensions of Teacher Self-Efficacy and Relations with Strain Factors, Perceived 
Collective Teacher Efficacy, and Teacher Burnout. Journal of Educational Psychology, 99, 611-625. http://psycnet.apa.org/doi/10.1037/0022-0663.99.3.611 http://dx.doi.org/10.1037/0022-0663.99.3.611

Skaalvik, E. M., \& Skaalvik, S. (2009). Does School Context Matter? Relations with Teacher Burnout and Job Satisfaction. Teaching and Teacher Education, 25, 518-524. http://dx.doi.org/10.1016/j.tate.2008.12.006

Skaalvik, E. M., \& Skaalvik, S. (2010). Teacher Self-Efficacy and Teacher Burnout: A Study of Relations. Teaching and Teacher Education, 26, 1059-1069. http://dx.doi.org/10.1016/j.tate.2009.11.001

Skaalvik, E. M., \& Skaalvik, S. (2011a). Teacher Job Satisfaction and Motivation to Leave the Teaching Profession: Relations with School Context, Feeling of Belonging, and Emotional Exhaustion. Teaching and Teacher Education, 27, 10291038. http://dx.doi.org/10.1016/j.tate.2011.04.001

Skaalvik, E. M., \& Skaalvik, S. (2011b). Teachers' Feeling of Belonging, Exhaustion, and Job Satisfaction: The Role of Goal Structure and Value Consonance. Anxiety, Stress, and Coping: An international Journal, 24, 369-385. http://dx.doi.org/10.1080/10615806.2010.544300

Skaalvik, E. M., \& Skaalvik, S. (2013). School Goal Structure: Associations with Students’ Perception of Their Teachers as Emotionally Supportive, Academic Self-Concept, Intrinsic Motivation, and Help Seeking Behavior. International Journal of Educational Research, 61, 5-14. http://dx.doi.org/10.1016/j.ijer.2013.03.007

Skaalvik, E. M., \& Skaalvik, S. (2014). Teacher Self-Efficacy and Perceived Autonomy: Relations with Teacher Engagement, Job Satisfaction, and Emotional Exhaustion. Psychological Reports, 114, 68-77.

Skaalvik, E. M., \& Skaalvik, S. (2015). Job Satisfaction, Stress, and Coping Strategies in the Teaching Profession. What Do the Teachers Say? International Education Studies, 8, 181-192. http://dx.doi.org/10.2466/14.02.PR0.114k14w0

Statistics Norway (2015). Gjennomstrømning i videregående opplæring, 2009-2014. https://www.ssb.no/utdanning/statistikker/vgogjen/aar/2015-06-04

Statistics Norway (2016). Nøkkeltall for utdanning. https://www.ssb.no/utdanning/nokkeltall/utdanning

Stoeber, J., \& Rennert, D. (2008). Perfectionism in School Teachers: Relations with Stress Appraisals, Coping Styles, and Burnout. Anxiety, Stress \& Coping, 21, 37-53. http://dx.doi.org/10.1080/10615800701742461

Tschannen-Moran, M., \& Woolfolk Hoy, A. (2001). Teacher Efficacy: Capturing an Elusive Construct. Teaching and Teacher Education, 17, 783-805. http://dx.doi.org/10.1016/S0742-051X(01)00036-1

Weiss, E. M. (1999). Perceived Workplace Conditions and First-Year Teachers' Morale, Career Choice Commitment, and Planned Retention: A Secondary Analysis. Teaching and Teacher Education, 15, 861-879. http://dx.doi.org/10.1016/S0742-051X(99)00040-2

Zembylas, M., \& Papanastasiou, E. (2006). Sources of Teacher Job Satisfaction and Dissatisfaction in Cyprus. Compare: A Journal of Comparative and International Education, 36, 229-247. http://dx.doi.org/10.1080/03057920600741289

Zimmerman, B. J., \& Cleary, T. J. (2006). Adolescents’ Develeopment of Personal Agency. The Role of Self-Efficacy Beliefs and Self-Regulatory Skills. In F. Pajares, \& T. Urdan (Eds.), Self-Efficacy Beliefs of Adolecents (pp. 45-69). Greenwich: Information Age.

\section{Submit or recommend next manuscript to SCIRP and we will provide best service for you:}

Accepting pre-submission inquiries through Email, Facebook, LinkedIn, Twitter, etc. A wide selection of journals (inclusive of 9 subjects, more than 200 journals)

Providing 24-hour high-quality service

User-friendly online submission system

Fair and swift peer-review system

Efficient typesetting and proofreading procedure

Display of the result of downloads and visits, as well as the number of cited articles

Maximum dissemination of your research work

Submit your manuscript at: http://papersubmission.scirp.org/ 